This is the post print version of the article, which has been published in Acta Paediatrica. 2017, 106 (12),

\title{
Low age, low birth weight and congenital heart disease are risk factors for intensive care in infants with bronchiolitis
}

Minna Mecklin ${ }^{1}$, Paula Heikkilä ${ }^{1}$, Matti Korppi ${ }^{1}$

${ }^{1}$ Tampere Center for Child Health Research, University of Tampere and Tampere University Hospital, Tampere, Finland

Short title: Risk factors for intensive care in bronchiolitis

Corresponding author: Minna Mecklin, MD, Tampere Center for Child Health Research, Lääkärinkatu 1, FI-33014 University of Tampere, Tampere, FINLAND.

Tel +358 505208114. Email minna.mecklin@fimnet.fi

Conflicts of interest: None

Finance: Minna Mecklin and Paula Heikkilä received grants from the Tampere Tuberculosis Foundation.

The paper was presented as a poster in the European Respiratory Society Annual Meeting 2016 in London, the UK. 


\begin{abstract}
Aim: This study evaluated the incidence and risk factors for intensive care and respiratory support in infant bronchiolitis.
\end{abstract}

Methods: We carried out a retrospective descriptive case-control study on 105 patients treated in the paediatric intensive care unit (PICU) and 210 controls treated in the emergency department or on the paediatric ward in Tampere University Hospital in Finland between 2000-2015. Statistically significant risk factors in non-adjusted analyses were included in the adjusted logistic regression.

Results: The average age-specific annual incidence of bronchiolitis requiring PICU admission under the age of 12 months was 1.5/1,000/year (range 0.18-2.59). Half of those were born prematurely at $<37$ gestational weeks. Other Independently significant risk factors for PICU admission were: being less than two months old (adjusted odds ratio, aOR 11.5), birth weight $<2,000 \mathrm{~g}(\mathrm{aOR} 15.9)$, congenital heart disease (aOR 15.9), the presence of apnoea (aOR 7.2) and the absence of wheezing (aOR 2.2). Significant risk factors for needing respiratory support were birth weight of $<2,000 \mathrm{~g}$, age of less than two months and congenital heart disease.

Conclusion: Less than $0.1 \%$ of infants under the age of 12 months were admitted to the PICU for bronchiolitis. Low age, low birth weight or prematurity and congenital heart disease were independently significant risk factors for both intensive care and respiratory support.

Keywords: Bronchiolitis, infant, intensive care, respiratory support, risk factors, congenital heart disease.

\title{
Key notes
}

- Six per cent of infants admitted for bronchiolitis at age $<12$ months need intensive care and half of them are born prematurely.

- Age less than 2 months, birth weight less than 2,000g and congenital heart disease predicted severe bronchiolitis and need for intensive care and respiratory support in adjusted analyses.

- Young infants with bronchiolitis, especially those with heart disease, require careful monitoring in hospital. 


\section{INTRODUCTION}

Bronchiolitis is the most common infectious cause of hospitalisation in infants. Most bronchiolitis patients have an uneventful course treated at home, but about $3 \%$ of those under 24 months of age are hospitalised $(1,2)$ and $2 \%$ to $3 \%$ of those hospitalised need mechanical ventilation (3). A Finnish study found that,-on average, 37 per 1,000 infants aged less than six months were admitted to the emergency department (ED) each year due to viral bronchiolitis and $70 \%$ of them, meaning $2.6 \%$ of all infants, were hospitalised. Furthermore, $6.1 \%$ needed treatment in the paediatric intensive care unit (PICU), which equated to an incidence of $2.3 / 1,000 /$ year in this age-specific population (4). Another Finnish study found that the rate of PICU treatment was $6.3 \%$ among those admitted to the ED due to bronchiolitis at less than 12 months of age (5).

Previous studies have identified several risk factors for severe bronchiolitis requiring hospitalisation, such as prematurity, young age, environmental factors like passive smoking and crowded households and underlying diseases like chronic lung disease (CLD), congenital heart disease (CHD) and some neurological syndromes $(3,6)$. Likewise, previous studies have identified risk factors associated with severe bronchiolitis requiring mechanical ventilation, such as being under two months of age, maternal smoking during pregnancy, Caesarean section delivery, birth weight less than $2,300 \mathrm{~g}$, reporting apnoea, inadequate oral intake, oxygen saturation less than $85 \%$ in room air and respiratory rate more than 70 breaths per minute (7-9). However, these previous prospective studies from the US comprised infants aged more than 12 months and those with recurrent 
wheeze $(7,8,10)$, which does not fit the current European definition of bronchiolitis (11).

The aim of this retrospective case-control study was to evaluate the incidence of, and the risk factors for, intensive care and respiratory support in infants admitted to a Finnish hospital for bronchiolitis at less than 12 months of age in 2000-2015. 


\section{PATIENTS AND METHODS}

This one-centre case-control study was based on a retrospective review of the electronic patient files of Tampere University Hospital, Tampere, Finland, for the years 2000-2015 (12). It was carried out with the permission of the Chief Physician of the University Hospital. At the time of the study, the hospital provided inpatient care for a population of about 90,000 children aged less than 16 years and the population of infants aged less than 12 months ranged from 4,761 to 5,880 . In addition, the hospital provided paediatric intensive care for the population of about 10,000 infants aged less than 12 months from four surrounding central hospitals (12). All the central hospitals surrounding the University Hospital had facilities to provide non-invasive ventilation support such as nasal continuous positive airway pressure (nCPAP) during the surveillance period. The high flow nasal cannula (HFNC) treatment was introduced 2011 in the University Hospital of Tampere, and HFNC treatments were given first in the PICU, and since 2012 at the paediatric ward.

We identified all patients treated in the PICU at less than 12 months of age with the International Classification of Diseases $-10^{\text {th }}$ edition (ICD-10) codes of $\mathrm{J} 10^{\star}-18^{*}, \mathrm{~J} 20^{*}-22^{*}, \mathrm{~J} 45^{*}$ or $\mathrm{J} 46^{*}$ during $2000-2015$. We found 179 infants. One of the authors $(\mathrm{PH})$ reviewed all the 179 patient files, checked the established diagnoses and the registered clinical findings and assessed the final bronchiolitis diagnoses for this study. Bronchiolitis was defined as the first episode of expiratory breathing difficulty, with or without audible wheezing, associated with a lower respiratory tract infection (12). We excluded infants with recurrent wheezing $(n=11)$, blood culture-positive bacterial infections $(n=1)$ and tense alveolar infiltrates in chest radiographs on admission that suggested bacterial pneumonia $(n=26)$. Additionally, 36 
infants were treated in the PICU for some other reason than bronchiolitis. The chart review showed that 105 infants had bronchiolitis as their main diagnosis or treating bronchiolitis was the main reason they received intensive care and 83 bronchiolitis patients were from Pirkanmaa (Tampere) Hospital District. Out of the 105 cases 34 infants were treated first on the paediatric ward and 71 were admitted directly to the PICU, including 22 patients from other surrounding hospitals. Infants were admitted to the PICU if they had acute worsening due the breathing such as increasing need of supplementary oxygen or increasing of respiratory work, or recurrent apnoea. The indications for PICU admission were the same for infants transferred from the surrounding hospitals and for those transferred from the wards or the ED of the University Hospital.

We selected two controls for each of these 105 cases, who were admitted for bronchiolitis with ICD-10 codes $\mathrm{J} 21^{*}$ just before and after the case. The controls were not admitted to the PICU and 146 of them were treated as inpatients on the ward and 64 as outpatients in the ED and were not admitted to the PICU. One of the authors $(\mathrm{PH})$ reviewed the hospital records of the 105 cases and 210 controls and completed the same structural form to collect medical data on both groups. This was carried out separately for findings and treatments in the ED, on the ward and in the PICU.

The data we collected comprised information on gender, gestational age classified with the cut-off points of 28,32 and 37 weeks, birth weight, and age and weight on admission for bronchiolitis. We also included the previous medical history, such as presence of respiratory distress syndrome (RDS), bronchopulmonary dysplasia (BPD), congenital heart disease (CHD), treatment with surfactant as a neonate, use of inhaled 
corticosteroids later, possible previous hospital admissions including treatment periods in the neonatal intensive care unit (NICU), presence of atopy such as doctor-diagnosed atopic dermatitis or food allergy and family histories of atopy or asthma. Audible wheezing, fine or coarse crackles on auscultation and dehydration if present were recorded on admission. The results of available viral antigen tests were collected. Secondary infections during hospitalisation, like otitis media, conjunctivitis and pneumonia, were recorded. Any therapies with nCPAP and mechanical ventilation were also recorded and both were considered as a respiratory support. Apnoea was defined as breathing pause with or without bradycardia and desaturation detected and recorded by the medical staff.

\section{Statistical methods}

IBM SPSS Statistic 23 (SPSS Inc., Chicago, USA) was used to analyse the data. The chi-square test and the frequency and percentage distributions with $95 \%$ confidence intervals $(95 \% \mathrm{Cl})$, were used in univariate statistical calculations. The two-tailed $p<0.05$ was considered as statistically significant finding. We used the Bonferroni correction by multiplying $p$ values by two in paired comparisons. Continuous variables were presented as medians with interquartile ranges (IQR). Odds ratios $(\mathrm{OR})$ and their $95 \%$ Cls were calculated first as non-adjusted and then in the multivariable logistic regression adjusted (aOR) for age, gender and risk factors that were significant in the non-adjusted analyses. Previous hospitalisation and previous use of corticosteroid were related to prematurity, and therefore, they were excluded from the final multivariable analyses. Even though several clinical findings were statistically significant in non-adjusted analyses, we decided to choose only wheezing sound to the final 
multivariable analyses due to its clear definition in the Finnish clinical practice. 
The median age was 1.7 months (IQR 0.9-3.5) in the PICU bronchiolitis group and 4.0 months (IQR 2.1-6.1) in the control bronchiolitis group $(p<0.001)$. Basic characteristics are presented in Table 1. Compared to the control group, infants treated in the PICU were younger and presented with higher comorbidities; they were born more often premature, had lower birth weights, and previously were treated more often in the hospital (Table 1). The risk of being admitted to the PICU was higher in infants aged less than two months (OR 5.0, 95\% Cl 3.0-8.4), born at $<37$ weeks (OR $7.2,95 \% \mathrm{Cl}$ 4.0-13.0), with birth weight under 2,500g (OR 14.6, 95\% Cl 6.7-31.9), and with apnoea (OR 39.7, 95\% Cl 9.3-170.3) (Table 1).

As expected, the same characteristics were associated with the need for respiratory support including nCPAP and/or mechanical ventilation during the PICU stay, as were associated for the PICU admission (Table S1). The risk for respiratory support was higher in infants aged less than two months (OR 3.8, 95\% Cl 2.0-7.2), born preterm at <37 weeks (OR 6.7, 95\% Cl 3.313.5), with birth weight under 2,500g (OR 8.7, 95\% $\mathrm{Cl} 4.2-18.1)$ and $\mathrm{CHD}$ (OR 5.0, 95\% Cl 1.9-15.1).

Wheezing was associated with less risk of PICU admission (OR 0.3, 95\% $\mathrm{Cl} 0.2-0.5)$ and less need for respiratory support (OR $0.4,95 \% \mathrm{CI} 0.2-0.7$ ) in those admitted (Table 1 and Table S1).

Apnoea was strongly associated with admission to the PICU (OR 39.7, 95\% Cl 9.3-170.3) and with the need for respiratory support (OR 6.7, 95\% Cl 3.0-15.0) (Table 1 and Table S1). In fact, apnoeas were only reported in one patient in the control group. In all, 40 infants presented with apnoea 
during the hospital stay and $40 \%$ of them needed respiratory support in the PICU (Table S2). Statistically significant risk factors for apnoea in inpatients were being less than two months of age (OR 5.4, 95\% Cl 2.6-10.9), born preterm at $<37$ weeks (OR 6.7, 95\% $\mathrm{Cl} 3.2-13.7$ ) and birth weight under 2,000g (OR 10.3, 95\% Cl 4.5-23.7).

In the multivariable logistic regression, the independently significant risk factors for PICU admission were being under two months of age (aOR $11.5,95 \% \mathrm{Cl} 5.1-25.8$ ), having low birth weight of $<2,000 \mathrm{~g}$ (aOR 15.9, 95\% Cl 2.4-107.3) and presenting with CHD (aOR 15.9, 95\% Cl 4.2-60.5). Reported apnoeas (aOR 7.2, 95\% Cl 1.4-36.1) and absence of wheezing (aOR 2.2, 95\% Cl 1.1-4.5) retained but premature birth lost the statistical significance (Table 2).

In the multivariable logistic regression, independently significant risk factors for the need for respiratory support, namely mechanical ventilation or nCPAP, were being less than two months of age (aOR 10.2, 95\% $\mathrm{Cl} 3.0$ 33.8), low birth weight of $<2,000 \mathrm{~g}(\mathrm{aOR} 4.9,95 \% \mathrm{Cl} 1.1-21.4)$ and $\mathrm{CHD}$ (aOR 13.0, 95\% $\mathrm{Cl}$ 2.8-60.9). Apnoea, preterm birth and absence of wheezing lost their statistical significance (Table 3).

Since $46 \%$ of the PICU admissions were associated with premature birth, we performed supplementary analyses by excluding birth weight from the model. In this model, premature birth was an independently significant risk factor for PICU admissions (aOR 4.4, 95\% $\mathrm{Cl} 1.2-9.8)$ and respiratory support (aOR 3.8, 95\% Cl 1.7-8.9). 
The annual number of the patients varied between one and 14 . The mean number of children aged less than 12 months in the population was 5,335 and varied between 4,761 and 5,880. These figures allowed us to calculate the population-based incidences. The age-specific annual incidence varied a lot, from 0.18/1,000/year to 2.59/1,000/year (mean 1.5) (Figure 1). 
There were four main results in this 16-year retrospective, one-centre, case-control study on the need for intensive care in infants with bronchiolitis at less than 12 months of age. First, the age-specific annual incidence varied considerably, from $0.18 / 1,000 /$ year to $2.59 / 1,000 /$ year. Second, an age of less than two months, birth weight under $2,000 \mathrm{~g}$ or prematurity under 37 weeks of gestation, and CHD were independently significant risk factors for PICU admissions and the need for respiratory support. Third, the presence of apnoea was associated to the need for intensive care. Fourth, audible wheezes and coarse crackles were, interestingly, more common in controls treated in the ED or on the ward than in cases treated in the PICU for bronchiolitis.

A Finnish study found that the incidence of bronchiolitis admissions to the ED at less than six months of age was $37 / 1,000 /$ year and the age-specific population-based incidence of bronchiolitis treated in the PICU was $2.3 / 1,000 /$ year in that age-specific population (4). The incidence was 1.5 times higher than the mean incidence of $1.5 / 1,000 /$ year in the present study, but the annual incidence varied considerably. This variation was due to low number of infants treated annually in the PICU and variations of respiratory syncytial virus epidemics. The figures for the need of mechanical ventilation among those admitted to the PICU were $13 \%$ in the earlier study (4) and $20 \%$ in the current study. In the most recent Finnish study, the PICU treatment rate was $6.3 \%$ among those hospitalised for bronchiolitis at less than 12 months of age (5), but population-based incidence figures could not be calculated in that study. In England, admission rates to the PICU ranged from 1.3 to 1.6 per 1,000 infants at less 
than 12 months of age between 2004 and 2012 (13). These incidence figures are surprisingly similar to the mean incidence in the present study. In another study, based on the nationally representative database on paediatric hospitalisations in the US, the need of mechanical ventilation increased between 2000 and 2009 (3). Although the annual incidences varied considerably in the present study, no such trends were seen.

Several studies have evaluated clinical factors associated with severe bronchiolitis defined with different outcomes, such as admission to the PICU (7,10,14-16), need for mechanical ventilation (7-9) or use of nCPAP (17). Five studies were carried out prospectively $(7-10,15)$. However, none of the previous study groups were entirely comparable to our study group. Some studies included children over 12 months old $(8,10,15,16)$ and some included children with episodes of previous wheezing $(8,10,16,17)$. In addition, some studies excluded children with an underlying disease and preterm birth $(9,14,15)$.

In line with our findings, PICU admissions and/or the need for respiratory support were predicted by young age $(8-10,15,16)$ and low birth weight $(7,8)$ in many studies. Two prospective multi-centre studies highlighted being less than two months old as a risk factor for PICU admission (10) and respiratory support (8). In the present adjusted analyses, infants who were less than two months old had an 11.5-fold risk for PICU admission and a 10.2-fold risk for needing respiratory support. Similarly, an Italian study that used adjusted analyses, confirmed that an age of less than one month predicted admission to the PICU and the need for respiratory support in hospitalised infants with bronchiolitis under the age of 12 months (9). We found that birth weight less than $2,000 \mathrm{~g}$ was an independently significant 
risk factor for PICU admission and respiratory support. Nearly the same birth weight of less than 2,300g was the respective cut-off limit that increased the risk of both intensive care and respiratory support in two other studies $(7,8)$.

Prematurity is a known risk factor for needing hospitalisation for severe bronchiolitis $(18,19)$. Only a few studies have identified premature birth as a risk factor for PICU admission or the need for respiratory support (16). A retrospective hospital chart review published in 2015 concluded that premature birth was associated to PICU admission but not to the length of PICU stay or treatment with mechanical ventilation (16). We found that those infants with bronchiolitis who were born preterm had a 7.2-fold risk of being admitted to the PICU and a 6.7 -fold risk for needing respiratory support. Preterm birth was an independently significant risk factor if low birth weight was not in the multivariable model, but due to interaction, lost its significance, if low birth weight was in the model.

$\mathrm{CHD}$ is associated with higher hospitalisation rates in infants with bronchiolitis (20) and haemodynamically significant CHD is a risk factor for severe bronchiolitis $(18,21)$. Some earlier retrospective case-control studies focusing on complicated RSV infections have identified $\mathrm{CHD}$ as a risk factor for PICU admission, need of respiratory support, as well as long duration of ventilation and PICU stay, in infants with bronchiolitis $(22,23)$. In our present retrospective 16-year case-control study all the infants with $\mathrm{CHD}$ were more than 2 months of age. Finally, CHD was an independently significant risk factor for PICU admission and for respiratory support for infants older than 2 months, although, CHD was haemodynamically significant in less than $25 \%$ of $\mathrm{CHD}$ cases. 
As expected, apnoea was an independently significant risk factor for PICU admission. A previous prospective multi-centre study described apnoea as an independently significant risk factor for respiratory support (8), but we were not able to confirm that result, probably due to our retrospectively collected data on apnoea based on entries in hospital records. In a previous study, infants with apnoea were younger, more likely to be born preterm and had lower birth weights (24), in accordance with our current observations. A prospective multi-centre cohort study showed that $56 \%$ of the 108 bronchiolitis patients with documented apnoeas during their inpatient stay required intensive care (24). In our study, 93\% of infants with apnoeas during hospitalisation were admitted to the PICU and half of them required respiratory support.

In the present case-control study, audible wheezes and coarse crackles were more common among patients discharged from the ED or treated on the ward compared to those treated in the PICU. This was in line with a previous study on 583 children hospitalised for bronchiolitis at less than 24 months of age, which reported that wheezing was more common among those treated on the ward (80\%) than in the PICU (60\%) (10). It is possible that wheezing indicates a less invasive disease and more reactive airways and that bronchiolitis with wheezing may be the first sign of asthma (25). There is some indirect evidence for this assumption, since wheezing infants seem to be older (6) and to respond better to bronchodilators (26), have more subsequent wheezing (27) and are more likely to be associated with viruses other than respiratory syncytial virus (25), compared to nonwheezing infants with bronchiolitis. In particular, the first wheezing episode 
associated with rhinovirus infection may the first sign of childhood asthma (28).

The strength of this study was were the long-term follow-up time of 16 years and carefully registered clinical data on admission and during hospitalisation in infancy, even though it was collected retrospectively. However, there was some information that was insufficient, such as information about parental smoking or the non-systematic examination of viral findings. One of the authors reviewed all the patient records after the cases were identified from the electronic registers. This means that the established diagnoses were not accepted directly, but were always revisited based on the information registered in the patient records by the doctors and nurses.

The main shortcoming of this study was that the design was retrospective. On the other hand, organising prospective surveillance time that is long enough including enough patients is laborious and expensive. The other shortcoming of this one-centre study was the small number of patients, even though the surveillance period was as long as 16 years.

\section{CONCLUSION}

The average age-specific annual incidence of bronchiolitis requiring intensive care at the age of less than 12 months was 1.5/1000/year, but varied considerably. The independently significant risk factors for PICU admission and respiratory support were age less than two months, birth weight under $2,000 \mathrm{~g}$ or prematurity under 37 weeks and CHD. 


\section{Funding}

This study was funded by The Tampere Tuberculosis Foundation.

\section{Abbreviations}

aOR, adjusted odds ratio; ED, emergency department; CHD, congenital heart disease; CLD, chronic lung disease; HFNC, high flow nasal cannula; nCPAP, nasal continuous positive airway pressure; IQR, interquartile range; RDS, respiratory distress syndrome; BPD, bronchopulmonary dysplasia; NICU, neonatal intensive care unit; OR, odds ratio; PICU, paediatric intensive care unit; $95 \% \mathrm{Cl}, 95 \%$ confidence intervals. 


\section{REFERENCES}

1. Shay DK, Holman RC, Newman RD, Liu LL, Stout JW, Anderson LJ. Bronchiolitisassociated hospitalizations among US children, 1980-1996. JAMA 1999; 282:1440-1446.

2. Smyth RL, Openshaw PJ. Bronchiolitis. Lancet 2006; 368: 312-322.

3. Hasegawa K, Tsugawa Y, Brown DF, Mansbach JM, Camargo CA,Jr. Temporal trends in emergency department visits for bronchiolitis in the United States, 2006 to 2010. Pediatr Infect Dis J 2014; 33:11-18.

4. Pruikkonen $\mathrm{H}$, Uhari $\mathrm{M}$, Dunder $\mathrm{T}$, Pokka $\mathrm{T}$, Renko $\mathrm{M}$. Infants under 6 months with bronchiolitis are most likely to need major medical interventions in the 5 days after onset. Acta Paediatr 2014; 10:1089-1093.

5. Jartti T, Aakula M, Mansbach JM, Piedra PA, Bergroth E, Koponen P, et al. Hospital lengthof-stay is associated with rhinovirus etiology of bronchiolitis. Pediatr Infect Dis J 2014; 33:829-834.

6. Zorc JJ, Hall CB. Bronchiolitis: recent evidence on diagnosis and management. Pediatrics $2010 ; 2: 342-349$.

7. Hasegawa K, Pate BM, Mansbach JM, Macias CG, Fisher ES, Piedra PA, et al. Risk factors for requiring intensive care among children admitted to ward with bronchiolitis. Acad Pediatr 2015; $1: 77-81$.

8. Mansbach JM, Piedra PA, Stevenson MD, Sullivan AF, Forgey TF, Clark S, et al. Prospective multicenter study of children with bronchiolitis requiring mechanical ventilation. Pediatrics 2012; 130:492-500.

9. Papoff P, Moretti C, Cangiano G, Bonci E, Roggini M, Pierangeli A, et al. Incidence and predisposing factors for severe disease in previously healthy term infants experiencing their first episode of bronchiolitis. Acta Paediatr 2011; 100:17-23. 
10. Damore D, Mansbach JM, Clark S, Ramundo M, Camargo CA,Jr. Prospective multicenter bronchiolitis study: predicting intensive care unit admissions. Acad Emerg Med 2008; 10:887-894.

11. Mecklin M, Hesselmar B, Qvist E, Wennergren G, Korppi M. Diagnosis and treatment of bronchiolitis in Finnish and Swedish children's hospitals. Acta Paediatr 2014; 103:946-950.

12. Heikkila P, Forma L, Korppi M. Hospitalisation costs for infant bronchiolitis are up to 20 times higher if intensive care is needed. Acta Paediatr 2015; 104:269-273.

13. Green CA, Yeates D, Goldacre A, Sande C, Parslow RC, McShane P, et al. Admission to hospital for bronchiolitis in England: trends over five decades, geographical variation and association with perinatal characteristics and subsequent asthma. Arch Dis Child 2016; 101:140-146.

14. Brooks AM, McBride JT, McConnochie KM, Aviram M, Long C, Hall CB. Predicting deterioration in previously healthy infants hospitalized with respiratory syncytial virus infection. Pediatrics 1999; 104:463-467.

15. Voets S, van Berlaer G, Hachimi-Idrissi S. Clinical predictors of the severity of bronchiolitis. Eur J Emerg Med 2006; 13:134-138.

16. Sala KA, Moore A, Desai S, Welch K, Bhandari S, Carroll CL. Factors associated with disease severity in children with bronchiolitis. J Asthma 2015; 52:268-272.

17. Evans J, Marlais M, Abrahamson E. Clinical predictors of nasal continuous positive airway pressure requirement in acute bronchiolitis. Pediatr Pulmonol 2012; 47:381-385.

18. American Academy of Pediatrics Committee on Infectious Diseases, American Academy of Pediatrics Bronchiolitis Guidelines Committee. Updated guidance for palivizumab prophylaxis among infants and young children at increased risk of hospitalization for respiratory syncytial virus infection. Pediatrics 2014; 134:415-420.

19. Weisman L. Populations at risk for developing respiratory syncytial virus and risk factors for respiratory syncytial virus severity: infants with predisposing conditions. Pediatr Infect Dis J 2003; 22:S33-39. 
20. Meberg A, Bruu AL. Respiratory syncytial virus infections in congenital heart defects-hospitalizations and costs. Acta Paediatr 2006; 95:404-406.

21. Chu PY, Hornik CP, Li JS, Campbell MJ, Hill KD. Respiratory syncytial virus hospitalisation trends in children with haemodynamically significant heart disease, 1997-2012. Cardiol Young 2016; 10:1-10.

22. Buckingham SC, Quasney MW, Bush AJ, DeVincenzo JP. Respiratory syncytial virus infections in the pediatric intensive care unit: clinical characteristics and risk factors for adverse outcomes. Pediatr Crit Care Med 2001; 2:318-323.

23. Purcell K, Fergie J. Driscoll Children's Hospital respiratory syncytial virus database: risk factors, treatment and hospital course in 3308 infants and young children, 1991 to 2002. Pediatr Infect Dis J 2004; 23:418-423.

24. Schroeder AR, Mansbach JM, Stevenson M, Macias CG, Fisher ES, Barcega B, et al. Apnea in children hospitalized with bronchiolitis. Pediatrics 2013; 132:1194-1201.

25. Jartti T, Makela MJ, Vanto T, Ruuskanen O. The link between bronchiolitis and asthma. Infect Dis Clin North Am 2005; 19:667-689.

26. Skjerven HO, Hunderi JO, Brugmann-Pieper SK, Brun AC, Engen H, Eskedal L, et al. Racemic adrenaline and inhalation strategies in acute bronchiolitis. N Engl J Med 2013; 368:2286-2293.

27. Chang TS, Lemanske RF,Jr, Guilbert TW, Gern JE, Coen MH, Evans MD, et al. Evaluation of the modified asthma predictive index in high-risk preschool children. J Allergy Clin Immunol Pract 2013; 1:152-156.

28. Kotaniemi-Syrjanen A, Reijonen TM, Korhonen K, Waris M, Vainionpaa R, Korppi M. Wheezing due to rhinovirus infection in infancy: Bronchial hyperresponsiveness at school age. Pediatr Int 2008; 50:506-510. 
Table 1. Basic and clinical data presented separately for 105 infants treated due to bronchiolitis in the paediatric intensive care unit (cases) and for $\mathbf{2 1 0}$ controls treated due to bronchiolitis in the emergency department or at the ward.

\begin{tabular}{|c|c|c|c|c|c|}
\hline Characteristic & $\begin{array}{l}\text { Cases } \\
n=105(\%)\end{array}$ & $\begin{array}{l}\text { Controls } \\
n=210(\%)\end{array}$ & OR & $95 \% \mathrm{Cl}$ & $p$-value \\
\hline Gender (males) & $61(58)$ & $108(51)$ & 1.31 & $0.82-2.10$ & 0.263 \\
\hline Age $<2$ months & $60(57)$ & $44(21)$ & 5.0 & $3.00-8.38$ & $<0.001$ \\
\hline $0-0.99$ months & $32(31)$ & $14(7)$ & 6.1 & $3.10-12.15$ & 0.001 \\
\hline 1-1.99 months & $28(38)$ & $30(15)$ & 3.4 & $1.87-6.35$ & $0.001^{a}$ \\
\hline 2.0 months or more & $45(43)$ & $166(79)$ & - & - & - \\
\hline $\begin{array}{c}\text { Prematures }(<37 \text { weeks }) \\
<28 \text { weeks }\end{array}$ & $\begin{array}{l}45 / 97(46) \\
12(12)\end{array}$ & $\begin{array}{l}22 / 204(11) \\
1(1)\end{array}$ & $\begin{array}{l}7.16 \\
28.7\end{array}$ & $\begin{array}{l}3.95-12.99 \\
3.67-223.88\end{array}$ & $\begin{array}{l}<0.001 \\
0.001\end{array}$ \\
\hline $\begin{array}{c}28-31+6 \text { weeks } \\
32-36+6 \text { weeks } \\
>37 \text { weeks } \\
\text { Birth weight <2500g }\end{array}$ & $\begin{array}{l}12(14) \\
21(22) \\
52(54) \\
40 / 99(40)\end{array}$ & $\begin{array}{l}1(1) \\
20(10) \\
182(89) \\
9 / 203(4)\end{array}$ & $\begin{array}{l}33.2 \\
3.7 \\
- \\
14.6\end{array}$ & $\begin{array}{l}4.24-259,87 \\
1.85-7.29 \\
- \\
6.70-31.87\end{array}$ & $\begin{array}{l}0.001^{a} \\
0.001^{a} \\
- \\
<0.001\end{array}$ \\
\hline $\begin{array}{c}<1000 \mathrm{~g} \\
1000-1499 \mathrm{~g} \\
1500-1999 \mathrm{~g} \\
2000-2499 \mathrm{~g} \\
>2500 \mathrm{~g}\end{array}$ & $\begin{array}{l}12(12) \\
8(8) \\
7(7) \\
13(13) \\
59(60) \\
57 / 100(57)\end{array}$ & $\begin{array}{l}1(1) \\
1(1) \\
1(1) \\
6(3) \\
194(96) \\
34 / 209(16)\end{array}$ & $\begin{array}{l}27.9 \\
20.4 \\
19.4 \\
7.1 \\
- \\
6.8\end{array}$ & $\begin{array}{l}3.57-217.61 \\
2.50-165.40 \\
2.35-160.79 \\
2.59-19.57 \\
- \\
3.98-11.71\end{array}$ & $\begin{array}{l}0.001 \\
0.001^{\mathrm{a}} \\
0.001^{\mathrm{a}} \\
0.001^{\mathrm{a}} \\
- \\
<0.001\end{array}$ \\
\hline NICU & $35 / 78(45)$ & $8 / 183(4)$ & 17.8 & $7.71-41.14$ & $<0.001$ \\
\hline Paediatric ward & $22 / 65(34)$ & $26(13)$ & 3.4 & $1.78-6.65$ & $<0.001$ \\
\hline $\begin{array}{l}\text { Underlying disease } \\
\mathrm{CHD}^{\mathrm{b}} \\
\mathrm{BPD} / \mathrm{RDS}^{\mathrm{b}}\end{array}$ & $\begin{array}{l}27(26) \\
13 / 89(15)^{\mathrm{c}} \\
8 / 88(9)\end{array}$ & $\begin{array}{l}12(6) \\
7 / 204(3) \\
1 / 198(1)\end{array}$ & $\begin{array}{l}5.6 \\
4.8 \\
19.7\end{array}$ & $\begin{array}{l}2.74-11.78 \\
1.85-12.53 \\
2.42-160.08\end{array}$ & $\begin{array}{l}<0.001 \\
0.001^{\mathrm{a}} \\
0.001^{\mathrm{a}}\end{array}$ \\
\hline $\begin{array}{l}\text { Other relevant } \\
\text { disease }^{\mathrm{b}}\end{array}$ & $12 / 91(13)$ & $6 / 203(3)$ & 5.0 & $1.81-13.75$ & $0.002^{a}$ \\
\hline Atopy & 3/102 (3) & $8(4)$ & 0.7 & $0.20-2.95$ & 0.696 \\
\hline Asthma in family & 10/103 (10) & $26(16)$ & 0.8 & $0.35-1.65$ & 0.486 \\
\hline $\begin{array}{l}\text { Current or earlier inhaled } \\
\text { corticosteroids }\end{array}$ & $9 / 104(9)$ & $2(1)$ & 9.9 & $2.09-46.48$ & $<0.001$ \\
\hline Respiratory syncytial virus & $59 / 92(64)$ & $66 / 127(51)$ & 1.7 & $0.98-2.96$ & 0.056 \\
\hline Apnoea & $29(27)$ & $2(1)$ & 39.7 & $9.25-170.33$ & $<0.001$ \\
\hline Tachypnea ( $\geq 50 / \mathrm{min})$ & $36(34)$ & $52(25)$ & 1.6 & $0.95-2.64$ & 0.076 \\
\hline Audible wheezing & $39(37)$ & $143(68)$ & 0.3 & $0.17-0.45$ & $<0.001$ \\
\hline Fine crackles & $26(25)$ & $27(13)$ & 2.2 & $1.23-4.06$ & 0.008 \\
\hline Coarse crackles & $33(31)$ & $97(46)$ & 0.5 & $0.33-0.87$ & 0.012 \\
\hline Dehydration & $10(10)$ & $8(4)$ & 2.7 & $1.91-6.95$ & 0.022 \\
\hline
\end{tabular}

${ }^{a}$ Bonferroni correction with multiplying the $p$ value with $2 .{ }^{b}$ Compared with patient without underlying disease. ${ }^{c} 7$ cases with haemodynamically significant $\mathrm{CHD}$. NICU, neonatal intensive care unit; CHD, congenital heart disease; BPD, bronchopulmonary dysplasia; RDS, respiratory distress syndrome. 
Table 2. Multivariate logistic regression: Risk factors for the need of intensive care among 315 infants admitted for bronchiolitis in 20002015.

\begin{tabular}{llll}
\hline Risk factor & $\begin{array}{l}\text { Adjusted Odds } \\
\text { ratio }\end{array}$ & $\mathbf{9 5} \% \mathbf{C l}$ & P-value \\
\hline Age $<2$ months & 11.50 & $5.12-25.80$ & $<0.001$ \\
Gender (male) & 1.81 & $0.88-3.74$ & 0.107 \\
Premature birth & 2.19 & $0.85-5.62$ & 0.105 \\
Birth weight under & 15.93 & $2.36-107.27$ & 0.004 \\
2000g & 15.85 & $4.15-60.50$ & $<0.001$ \\
CHD & 7.22 & $1.44-36.10$ & 0.016 \\
Apnoea & 2.19 & $1.08-4.47$ & 0.031 \\
Non-wheezing & & &
\end{tabular}

Area under the curve for predicted probability: 0.882 . Hosmer-Lemeshow test: $1.80, p$ 0.937. CHD; congenital heart disease. 
Table 3. Multivariate logistic regression: Risk factors for the need of respiratory support among 315 infants admitted for bronchiolitis in 2000-2015.

\begin{tabular}{llll}
\hline Risk factor & Adjusted Odds ratio & $\mathbf{9 5} \% \mathbf{C l}$ & P-value \\
& & & \\
\hline Age $<2$ months & 10.15 & $3.04-33.83$ & $<0.001$ \\
Gender (male) & 1.29 & $0.55-3.07$ & 0.560 \\
Premature birth & 2.32 & $0.82-6.53$ & 0.111 \\
Birth weight under & 4.87 & $1.11-21.42$ & 0.036 \\
2000g & 12.99 & $2.77-60.86$ & 0.001 \\
CHD & 1.62 & $0.51-5.14$ & 0.416 \\
Apnoea & 1.44 & $0.57-3.65$ & 0.440 \\
Non-wheezing & & &
\end{tabular}

Area under the curve for predicted probability: 0.864 . Hosmer-Lemeshow test: $2.03, p$ 0.917. CHD; congenital heart disease. 
Supplementary Table 1. Basic and clinical data presented separately for 45 infants with bronchiolitis requiring respiratory support (nasal CPAP and/or mechanical ventilation) treated and for 270 controls without need for respiratory support.

\begin{tabular}{|c|c|c|c|c|c|c|c|}
\hline Characteristic & $\begin{array}{l}\text { Respiratory } \\
\text { support } \\
n=45(\%)\end{array}$ & $\begin{array}{l}\mathrm{nCPAP} \\
\mathrm{n}=38^{\mathrm{a}}\end{array}$ & $\begin{array}{l}\text { Mechanical } \\
\text { ventilation } \\
n=21\end{array}$ & $\begin{array}{l}\text { No respiratory } \\
\text { support } \\
n=270(\%)\end{array}$ & OR & Cl 95\% & $\mathrm{p}$-value \\
\hline Gender (males) & $26(58)$ & 22 & 12 & $143(53)$ & 1.2 & $0.64-2.30$ & 0.549 \\
\hline Age $<2$ months & $27(60)$ & 22 & 16 & $77(29)$ & 3.8 & $1.96-7.22$ & $<0.001$ \\
\hline 0-0.99 months & $15(33)$ & 9 & 12 & $31(12)$ & 3.9 & $1.87-7.95$ & 0.001 \\
\hline 1-1.99 months & $12(40)$ & 10 & 7 & $46(19)$ & 2.8 & $1.26-6.21$ & $0.018^{b}$ \\
\hline $\begin{array}{l}2 \text { months or } \\
\text { more }\end{array}$ & $18(40)$ & 16 & 6 & $193(74)$ & - & - & - \\
\hline Prematures (<37 weeks) & $23 / 40(58)$ & 21 & 10 & $44 / 261(17)$ & 6.7 & $3.30-13.51$ & $<0.001$ \\
\hline$<28$ weeks & $6(17)$ & 6 & 2 & $7(3)$ & 6.4 & $2.03-20.18$ & 0.001 \\
\hline $28-31+6$ weeks & $6(18)$ & 6 & 2 & 7 (3) & 7.6 & $2.37-24.08$ & $0.001^{b}$ \\
\hline $32-36+6$ weeks & $11(39)$ & 9 & 6 & $30(12)$ & 4.7 & $2.00-10.94$ & $0.001^{b}$ \\
\hline$>37$ weeks & $17(43)$ & 15 & 8 & 217 (83) & - & - & - \\
\hline Birth weight $<2500 \mathrm{~g}$ & $21 / 41(51)$ & 19 & 9 & 28/261 (11) & 8.7 & $4.22-18.08$ & $<0.001$ \\
\hline$<1000 \mathrm{~g}$ & $6(15)$ & 6 & 1 & $7(3)$ & 6.2 & $1.98-19.57$ & 0.001 \\
\hline $1000-1499 g$ & $4(11)$ & 4 & 2 & $5(2)$ & 6.4 & $1.64-25.21$ & $0.006^{\mathrm{b}}$ \\
\hline $1500-1999 \mathrm{~g}$ & $4(13)$ & 3 & 2 & $4(2)$ & 9.1 & $2.15-38.37$ & $0.001^{b}$ \\
\hline $2000-2499 g$ & $7(26)$ & 6 & 4 & $12(5)$ & 6.8 & $2.41-19.19$ & $0.001^{b}$ \\
\hline$>2500 \mathrm{~g}$ & $20(49)$ & 17 & 10 & $233(89)$ & - & - & - \\
\hline Previous hospitalisation & $25 / 42(59)$ & 16 & 10 & $66 / 267(25)$ & 4.5 & $2.28-8.81$ & $<0.001$ \\
\hline NICU & 20/37 (54) & 19 & 7 & $23 / 224(10)$ & 10.3 & $4.73-22.37$ & $0.001^{b}$ \\
\hline Paediatric ward & $5 / 22(10)$ & 4 & 4 & 43/244 (18) & 1.4 & $0.48-3.93$ & $1.102^{\mathrm{b}}$ \\
\hline Underlying disease & $12(33)$ & 12 & 3 & $27(12)$ & 3.3 & $1.51-7.05$ & 0.002 \\
\hline $\mathrm{CHD}$ & $8(20)^{c}$ & 7 & 2 & $12(6)^{d}$ & 5.0 & $1.89-15.10$ & $<0.001^{b}$ \\
\hline BPD/RDS & $2(6)$ & 2 & 1 & $7(3)$ & 2.0 & $0.41-10.24$ & $0.752^{b}$ \\
\hline $\begin{array}{l}\text { Other relevant } \\
\text { disease }\end{array}$ & $4(11)$ & 3 & 1 & $14(6)$ & 2.0 & $0.63-6.54$ & $0.450^{\mathrm{b}}$ \\
\hline $\begin{array}{l}\text { Respiratory syncytial } \\
\text { virus }\end{array}$ & $28 / 41(68)$ & 22 & 14 & $98 / 178(55)$ & 1.8 & $0.90-3.78$ & 0.094 \\
\hline Apnoea & $14(31)$ & 13 & 10 & $17(6)$ & 6.7 & $3.02-14.95$ & $<0.001$ \\
\hline Tachypnea ( $\geq 50 / \mathrm{min})$ & $21(20)$ & 20 & 7 & $67(24)$ & 2.7 & $1.39-5.07$ & 0.002 \\
\hline Audible wheezing & $16(36)$ & 13 & 9 & $166(62)$ & 0.4 & $0.18-0.67$ & 0.001 \\
\hline Dehydration & $4(9)$ & 4 & 1 & $14(5)$ & 1.8 & $0.56-5.69$ & 0.322 \\
\hline
\end{tabular}

a 14 infants needed both nCPAP and mechanical ventilation. ${ }^{b}$ Bonferroni correction with multiplying the $p$ value with $2 .{ }^{c} 3$ cases of haemodynamically significant $C H D .{ }^{d} 4$ cases of haemodynamically significant CHD. nCPAP, nasal continous positive airway pressure; NICU; neonatal intensive care unit, CHD; congenital heart disease, BPD; bronchopulmonary dysplasia, RDS; respiratory distress syndrome. 


\section{Supplementary Table 2. Characteristics of infants with bronchiolitis presented separately for those $\mathbf{4 0}$ with apnoea and for those $\mathbf{2 7 5}$ without apnoea during hospital stay.}

\begin{tabular}{|c|c|c|c|c|c|}
\hline Characteristic & $\begin{array}{l}\text { Apnoea } n=40 \\
(\%)\end{array}$ & $\begin{array}{l}\text { No apnoea } \\
\mathrm{n}=275(\%)\end{array}$ & OR & $95 \% \mathrm{Cl}$ & $p$-value \\
\hline Gender (males) & $18(45)$ & $149(54)$ & 0.69 & $0.36-1.35$ & 0.277 \\
\hline $\begin{array}{l}\text { Age (months, median, } \\
\text { IQR) }\end{array}$ & $1.5(0.8-2.8)$ & $3.5(1.8-6.0)$ & - & - & $<0.001$ \\
\hline$<2$ months & $27(68)$ & $77(28)$ & 5.35 & $2.62-10.89$ & $<0.001$ \\
\hline $0-0.99$ months & $11(28)$ & 35 (13) & 2.60 & $1.19-5.67$ & 0.013 \\
\hline 1-1.99 months & $16(55)$ & $42(18)$ & 5.80 & $2.60-12.97$ & $0.001^{a}$ \\
\hline Prematures (<37 weeks) & $22 / 38(58)$ & $45 / 263(17)$ & 6.66 & $3.24-13.68$ & $<0.001$ \\
\hline$<28$ weeks & $8(21)$ & $5(2)$ & 13.76 & $4.23-44.76$ & $<0.001$ \\
\hline $28-31+6$ weeks & $5(17)$ & $8(3)$ & 6.25 & $1.90-20.56$ & $0.002^{a}$ \\
\hline $32-36+6$ weeks & $9(36)$ & $32(13)$ & 3.83 & $1.56-9.40$ & $0.004^{a}$ \\
\hline $\begin{array}{l}\text { Birth weight (g, median, } \\
\text { IQR) }\end{array}$ & $\begin{array}{l}2445(1325- \\
3520)\end{array}$ & $\begin{array}{l}3327(3055- \\
3700)\end{array}$ & - & - & $<0.001$ \\
\hline$<20000 \mathrm{~g}$ & $15 / 39(39)$ & $15 / 263(6)$ & 10.33 & $4.51-23.68$ & $<0.001$ \\
\hline $\begin{array}{l}<1000 \mathrm{~g} \\
1000-1499 \mathrm{~g} \\
1500-1999 \mathrm{~g}\end{array}$ & $\begin{array}{l}7(18) \\
3(9) \\
5(17)\end{array}$ & $\begin{array}{l}6(2) \\
6(2) \\
3(1)\end{array}$ & $\begin{array}{l}9.37 \\
4.33 \\
17.22\end{array}$ & $\begin{array}{l}2.97-29.61 \\
1.03-18.23 \\
3.88-76.53\end{array}$ & $\begin{array}{l}<0.001 \\
0.062^{a} \\
0.001^{a}\end{array}$ \\
\hline Underlying disease & $12(30)$ & $27(10)$ & 3.92 & $1.79-8.59$ & $<0.001$ \\
\hline $\mathrm{CHD}$ & $4(10)$ & $16(6)$ & 1.80 & $0.57-5.68$ & $0.311^{a}$ \\
\hline BPD/RDS & $5(15)$ & $4(2)$ & 11.12 & $2.82-43.82$ & $0.001^{a}$ \\
\hline $\begin{array}{l}\text { Other relevant } \\
\text { disease }\end{array}$ & $8(22)$ & $10(4)$ & 7.09 & $2.585-19.43$ & $0.001^{a}$ \\
\hline Respiratory syncytial virus & $21(53)$ & $104(39)$ & 1.72 & $0.883-3.3 .57$ & 0.108 \\
\hline PICU & $37(93)$ & $68(25)$ & 37.54 & $\begin{array}{l}11.218- \\
125.657\end{array}$ & $<0.001$ \\
\hline Respiratory support & $16(40)$ & $29(11)$ & 5.66 & $2.697-11.858$ & $<0.001$ \\
\hline nCPAP & $14(35)$ & $24(9)$ & 5.54 & $2.67-12.01$ & $<0.001$ \\
\hline Intubation & $10(26)$ & $10(4)$ & 9.14 & $3.510-23.787$ & $<0.001$ \\
\hline
\end{tabular}

${ }^{a}$ Bonferroni correction with multiplying the $p$ value with 2. IQR, interquartile range; CHD; congenital heart disease, BPD; bronchopulmonary dysplasia, RDS; respiratory distress syndrome, PICU; paediatric intensive care unit; nCPAP, nasal continuous positive airway pressure. 
Figure 1. Annual age-specific incidence of bronchiolitis infant treated in intensive care during the study period 2000-2015.

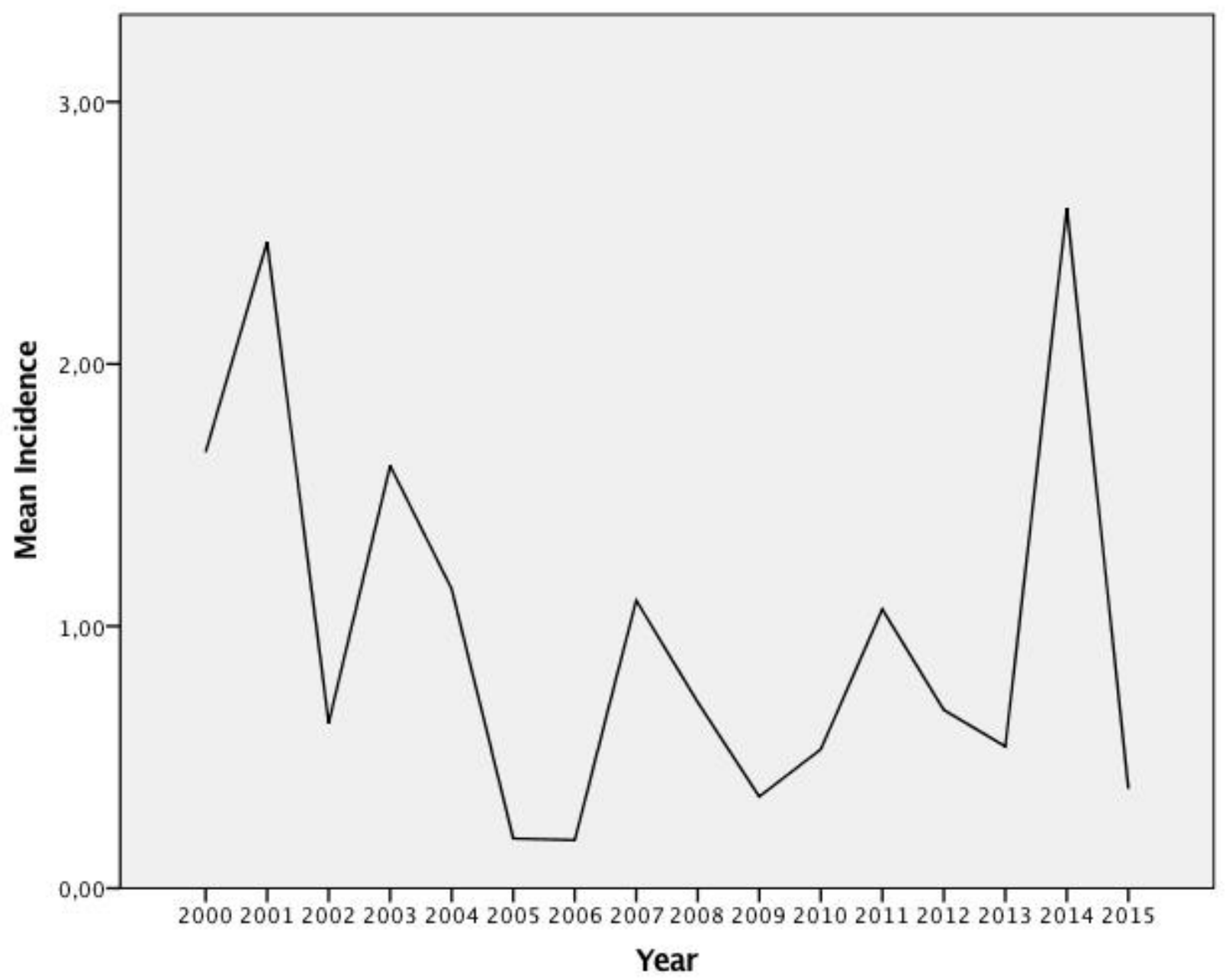

